A Kinetic Modeling study on the Oxidation of Primary Reference Fuel\#Toluene Mixtures Including Cross Reactions between Aromatics and Aliphatics

Yasuyuki Sakai, Akira Miyoshi, Mitsuo Koshi, William J. Pitz

January 10, 2008

32nd International Symposium on Combustion Montreal, Canada August 3, 2008 through August 8, 2008 
This document was prepared as an account of work sponsored by an agency of the United States government. Neither the United States government nor Lawrence Livermore National Security, LLC, nor any of their employees makes any warranty, expressed or implied, or assumes any legal liability or responsibility for the accuracy, completeness, or usefulness of any information, apparatus, product, or process disclosed, or represents that its use would not infringe privately owned rights. Reference herein to any specific commercial product, process, or service by trade name, trademark, manufacturer, or otherwise does not necessarily constitute or imply its endorsement, recommendation, or favoring by the United States government or Lawrence Livermore National Security, LLC. The views and opinions of authors expressed herein do not necessarily state or reflect those of the United States government or Lawrence Livermore National Security, LLC, and shall not be used for advertising or product endorsement purposes. 


\title{
A Kinetic Modeling Study on the Oxidation of Primary Reference Fuel-Toluene Mixtures Including Cross Reactions between Aromatics and Aliphatics
}

\author{
Yasuyuki Sakai ${ }^{1}$, Akira Miyoshi ${ }^{1}$, Mitsuo Koshi ${ }^{1}$ and William J. Pitz ${ }^{2}$ \\ ${ }^{1}$ Department of Chemical System Engineering, the University of Tokyo, Tokyo, Japan \\ ${ }^{2}$ Chemical Sciences Division, Lawrence Livermore National Laboratory, CA, USA \\ *Corresponding Author \\ Mitsuo Koshi \\ 7-3-1 Hongo, Bunkyo-ku, Tokyo, Japan, 113-8656 \\ Phone: $+81-3-5841-7295$ \\ Fax: $+81-3-5841-7488$ \\ E-mail: koshi@chemsys.t.u-tokyo.ac.jp \\ Colloquium: Reaction Kinetics \\ Abstract length: 253 words \\ Total length: 5089 words (determined using "method 1") \\ Main text length: 3158 words (including reaction formulae) \\ References length: $(35+2) * 2.3 * 7.6=647$ words
}

Figures length: 1284 words

Fig. 1 length: $(48+10) * 2.2 * 1+15=143$

Fig. 2 length: $(63+10) * 2.2 * 1+45=206$

Fig. 3 length: $(62+10) * 2.2 * 1+19=178$

Fig. 4 length: $(57+10) * 2.2 * 1+36=184$

Fig. 5 length: $(63+10) * 2.2 * 1+28=189$

Fig. 6 length: $(63+10) * 2.2 * 1+34=195$

Fig. 7 length: $(64+10) * 2.2 * 1+26=189$ 


\section{Abstract}

A detailed chemical kinetic model for the mixtures of Primary Reference Fuel (PRF: n-heptane and iso-octane) and toluene has been proposed. This model is divided into three parts; a PRF mechanism [T. Ogura et al., Energy \& Fuels 21 (2007) 3233-3239], toluene sub-mechanism and cross reactions between PRF and toluene. Toluene sub-mechanism includes the low temperature kinetics relevant to engine conditions. A chemical kinetic mechanism proposed by Pitz et al. [Proc. the 2 nd Joint Meeting of the U.S. Combust. Institute (2001)] was used as a starting model and modified by updating rate coefficients. Theoretical estimations of rate coefficients were performed for toluene and benzyl radical reactions important at low temperatures. Cross-reactions between alkane, alkene, and aromatics were also included in order to account for the acceleration by the addition of toluene into iso-octane recently found in the shock tube study of the ignition delay [Y. Sakai et al, SAE 2007-01-4014 (2007)]. Validations of the model were performed with existing shock tube and flow tube data. The model well predicts the ignition characteristics of toluene and PRF/Toluene mixtures under the wide range of temperatures $(500-1700 \mathrm{~K})$ and pressures $(2-50 \mathrm{~atm})$. It is found that reactions of benzyl radical with oxygen molecule determine the reactivity of toluene at low temperature. Although the effect of toluene addition to iso-octane is not fully resolved, the reactions 
of alkene with benzyl radical have the possibility to account for the kinetic interactions between PRF and toluene.

Keywords: modeling, PRF/toluene, cross reaction, ignition 


\section{Introduction}

Practical fuels such as gasoline and diesel fuel contain a large number of hydrocarbons and therefore it is impossible to run a simulation which includes all of chemical and physical properties. However, the ignition characteristics of practical fuels can be reproduced with several representative components of real fuels. Gauthier et al. [1] have shown in their shock tube study that ignition delay times for RD387 gasoline were successfully reproduced by a ternary model fuel (n-heptane/17\%, iso-octane/63\%, and toluene $/ 20 \%$ by liquid volume) at the range of temperatures from 850 to $1250 \mathrm{~K}$, pressures from 15 to 60 atm, equivalence ratio of $0.5,1.0$, and 2.0 , exhaust gas recirculation loadings of 0,20 , and $30 \%$. This simpler representative fuel is termed the "surrogate fuel". In the review of Pitz et al. [2], they have recommended that a ternary mixture of Primary Reference Fuel (PRF: n-heptane and iso-octane) and toluene (hereafter PRF/Toluene) is suitable as a gasoline surrogate fuel for the purpose of Homogeneous Charge Compression Ignition (HCCI) engine simulation.

Chemical kinetic models of PRF/Toluene were proposed in several previous studies [3-7]. Recently, ignition delay times of toluene were measured using shock tube [8] and Rapid Compression Machine (RCM) [9] at pressures from 10 to $61 \mathrm{~atm}$ and temperatures 855 to $1400 \mathrm{~K}$. Sivaramakrishnan et al. [10] measured stable products 
using a High-Pressure single pulse Shock Tube (HPST) combined with a gas chromatography-mass spectrometry at pressures 22 to $550 \mathrm{~atm}$ and temperatures 1210 to $1480 \mathrm{~K}$. A detailed chemical kinetic model [11] was also constructed to predict these experiment data. Chaos et al. [7] measured stable species for the oxidation of PRF, toluene and their mixtures using Variable Pressure Flow Reactor (VPFR) at 12.5 atm and temperatures from 500 to $1000 \mathrm{~K}$. Their PRF/Toluene model is good agreement with their data. However, none of the kinetic models can explain the ignition characteristics over wide temperature and pressure ranges, and Pitz et al., [2] pointed out that the further understanding of the chemical kinetics of toluene combustion is required especially at low temperatures and high pressures to apply these models to HCCI combustion.

Chemical kinetic interactions between alkanes and aromatics can be significant in the combustion of PRF/Toluene mixtures. Generally, the interactions are discussed in terms of radical pool effects $[6,7,12]$. When the toluene is added to PRF, toluene acts as a radical scavenger and decreases the reactivity of mixtures. Vanhove et al. [13] investigated the oxidation of surrogate fuel mixtures composed of n-heptane, iso-octane, toluene, and 1-hexene by using a RCM below $900 \mathrm{~K}$. In their study, it is noted that the extrapolation of the ignition delay times of iso-octane/toluene mixture (iso-octane $65 \%$, 
toluene $35 \%)$ to higher temperatures $(\mathrm{T}>1100 \mathrm{~K})$ are shorter than those of pure iso-octane. Such acceleration effect of toluene addition was not observed in n-heptane/toluene mixtures. We also observed the acceleration by the addition of toluene to iso-octane at high temperatures [14]. Ignition delay times of PRF/Toluene were measured behind the reflected shock waves at 2 atm and temperatures 1200 to $1600 \mathrm{~K}$. It was found that ignition delay times of n-heptane increased with the addition of toluene, while those of iso-octane decreased with the addition of $0-50 \%$ toluene. Such effect of toluene addition could not be reproduced by any existing kinetic models.

In this study, we constructed a detailed chemical kinetic model for the oxidation of PRF/Toluene with focusing on the low temperature kinetics of toluene and kinetic interactions between PRF and toluene.

\section{Chemical kinetic modeling}

A chemical kinetic mechanism proposed by Pitz et al. [15] (hereafter Pitz model) as a starting model and modified it by updating rate constants mainly for toluene $\left(\mathrm{C}_{6} \mathrm{H}_{5} \mathrm{CH}_{3}\right)$ and benzyl radical $\left(\mathrm{C}_{6} \mathrm{H}_{5} \mathrm{CH}_{2}\right)$ reactions taken from recent studies and our own theoretical estimations. This toluene sub-mechanism is merged to the PRF model developed by Ogura et al. [16]. Cross reactions between PRF and toluene were also 
added into the model. Thus our PRF/Toluene model contains 783 species and 2883 reactions. This kinetic mechanism with thermochemical data is available form the author on demand.

\subsection{Toluene sub-mechanism}

Our modifications to the Pitz model are summarized as follows. First we have updated rate constants and added new reactions based on recent published studies. The rate constants of toluene with molecular oxygen [17], OH radical [18], $\mathrm{H}$ radical [19] and its unimolecular decomposition reactions [20] were updated. Seta et al. [18] measured the overall rate constants of $\mathrm{C}_{6} \mathrm{H}_{5} \mathrm{CH}_{3}+\mathrm{OH}$ reactions at high temperatures and estimated channel specific rate coefficients of this reaction on the basis of RRKM-master equation analysis. They found that the abstraction channels from phenyl-H are not negligible at higher temperatures. For example, the ratio of abstraction from methyl-H to that of phenyl-H is estimated to be $2.2: 1$ at $1500 \mathrm{~K}$. In the chemical kinetic model of toluene oxidation proposed by Bounaceur et al. [21], the phenyl-H abstraction reactions by $\mathrm{OH}, \mathrm{H}, \mathrm{HO}_{2}$, and $\mathrm{CH}_{3}$ radicals to form methyl-phenyl radical $\left(\mathrm{C}_{6} \mathrm{H}_{4} \mathrm{CH}_{3}\right)$ and its subsequent reactions (especially, reactions to form cresol and cresoxy radicals) are included. These abstraction reactions of phenyl- $\mathrm{H}$ were added into the present model with the rate constants of Seta et al. for the reactions of $\mathrm{OH}$ radical and of 
Bounaceur et al. for the reactions of other radicals. Recombination reaction of benzyl radicals to form bibenzyl and its subsequent reactions [20] were also added because of their importance in low temperature kinetics.

Next, we estimated several rate constants that were not fully understood so far by experiments or theoretical studies. Sensitivity analysis shows that the abstraction reaction of toluene with phenoxy $\left(\mathrm{C}_{6} \mathrm{H}_{5} \mathrm{O}\right)$ radical, $(\mathrm{R} 1)$, has a high sensitivity to the ignition delay at low temperatures. $\mathrm{C}_{6} \mathrm{H}_{5} \mathrm{O}$ and formyl radical $(\mathrm{CHO})$ are produced by the reaction of benzyl radical with molecular oxygen. These reactions are the main pathways of toluene oxidation at low temperatures. Since there is no experimental or theoretical study on these reactions, rate constants of the abstraction reactions of toluene by $\mathrm{C}_{6} \mathrm{H}_{5} \mathrm{O}(\mathrm{R} 1)$ and $\mathrm{CHO}(\mathrm{R} 2)$ were computed on the basis of the Canonical Transition State Theory (CTST).

$$
\begin{aligned}
& \mathrm{C}_{6} \mathrm{H}_{5} \mathrm{CH}_{3}+\mathrm{C}_{6} \mathrm{H}_{5} \mathrm{O} \Leftrightarrow \mathrm{C}_{6} \mathrm{H}_{5} \mathrm{CH}_{2}+\mathrm{C}_{6} \mathrm{H}_{5} \mathrm{OH} \\
& \mathrm{C}_{6} \mathrm{H}_{5} \mathrm{CH}_{3}+\mathrm{CHO} \Leftrightarrow \mathrm{C}_{6} \mathrm{H}_{5} \mathrm{CH}_{2}+\mathrm{CH}_{2} \mathrm{O}
\end{aligned}
$$

Quantum chemical calculations were performed to obtain the height of energy barriers for those reactions using Gasussian03 package [22]. The optimized structure, vibrational frequencies and rotational constants of reactants, products and transition states were calculated at the B3LYP/6-311+G(d,p) level of theory and energies were calculated at 
the G3MP2//B3LYP/6-311+G(d,p) level of theory. The activation energy of (R1) and (R2) were found to be 16.4 and $19.6 \mathrm{kcal} / \mathrm{mol}$, respectively. The resulting rate constants are expressed as follows (in units of $\mathrm{cm}^{3}, \mathrm{~K}$, mol, cal).

$$
\begin{aligned}
& \mathrm{k}_{1}=5.431 \times 10^{12} \exp \left(-\frac{20923.0}{\mathrm{RT}}\right) \\
& \mathrm{k}_{2}=3.771 \times 10^{13} \exp \left(-\frac{23787.4}{\mathrm{RT}}\right)
\end{aligned}
$$

The rate constants of the reactions of benzyl radical with molecular oxygen were also estimated. Recently, Murakami et al. [23] calculated potential energy barriers for the various channels of the benzyl radical reaction with molecular oxygen at the CBSQB3 level of theory. They concluded that there are three main pathways to form benzyl-oxygen adduct $\left(\mathrm{C}_{6} \mathrm{H}_{5} \mathrm{CH}_{2} \mathrm{OO}\right)$, benzaldehyde $\left(\mathrm{C}_{6} \mathrm{H}_{5} \mathrm{CHO}\right)+\mathrm{OH}$ and $\mathrm{C}_{6} \mathrm{H}_{5} \mathrm{O}+\mathrm{CH}_{2} \mathrm{O}$. The $\mathrm{C}_{6} \mathrm{H}_{5} \mathrm{CH}_{2} \mathrm{OO}$ will further decompose to two channels; $\mathrm{C}_{6} \mathrm{H}_{5} \mathrm{CHO}+\mathrm{OH}$ and $\mathrm{C}_{6} \mathrm{H}_{5} \mathrm{O}+\mathrm{CH}_{2} \mathrm{O}$. The internal hydrogen abstractions in $\mathrm{C}_{6} \mathrm{H}_{5} \mathrm{CH}_{2} \mathrm{OO}$ have much higher activation energies than those decompositions from the chemically activated $\mathrm{C}_{6} \mathrm{H}_{5} \mathrm{CH}_{2} \mathrm{OO}$. As a result, the degenerated chain branching reactions, which are important in alkane oxidation, can be neglected at the temperatures relevant to combustion. Based on quantum chemical calculations of Murakami et al., the pressure dependent, channel specific rate constants of $\mathrm{C}_{6} \mathrm{H}_{5} \mathrm{CH}_{2}+\mathrm{O}_{2}$ reaction were evaluated by using Variflex program [24]. Results are included in our model. 
Channel specific rate constants of the reaction of benzyl radical with oxygen atom, which has high sensitivity to ignition delay at high temperature, are also evaluated. This reaction was studied experimentally by Hippler et al [25] and its net reaction rate was reported. Emdee et al. [26] estimated the branching ratio to be $3: 1$ for channels to yield $\mathrm{H}+\mathrm{C}_{6} \mathrm{H}_{5} \mathrm{CHO}$ and phenyl radical $\left(\mathrm{C}_{6} \mathrm{H}_{5}\right)+\mathrm{CH}_{2} \mathrm{O}$. Since the value of this branching ratio has rather large effects on the consecutive reactions in the toluene combustion, quantum chemical calculations were performed to obtain the energy diagram of $\mathrm{C}_{6} \mathrm{H}_{5} \mathrm{CH}_{2}+\mathrm{O}$ reaction. The optimized structure, vibrational frequencies and rotational constants were calculated at the B3LYP/6-31G(d) level of theory and energies were calculated at the G3MP2B3 level of theory. Resulting energy diagrams are shown in Fig. 1. The energy of the $\mathrm{C}_{6} \mathrm{H}_{5} \mathrm{CH}_{2}-\mathrm{O}$ adduct is $81.1 \mathrm{kcal} / \mathrm{mol}$ lower than that of reactants and there are two main channels for the decomposition of this chemically activated adduct. One is the channel to produce $\mathrm{H}+\mathrm{C}_{6} \mathrm{H}_{5} \mathrm{CHO}$ with the activation energy of $17.2 \mathrm{kcal} / \mathrm{mol}$ relative to the $\mathrm{C}_{6} \mathrm{H}_{5} \mathrm{CH}_{2}-\mathrm{O}$ adduct, and another is the channel to produce $\mathrm{C}_{6} \mathrm{H}_{5}+\mathrm{CH}_{2} \mathrm{O}$ without any transition state. The energies of these both channels are well below the reactants state, as shown in Fig. 1, and therefore, the product branching ratios are approximately given by the ratios of the micro-canonical rate constants $k(E)$. The ratio of $k(E)$ for the $\mathrm{H}+$ $\mathrm{C}_{6} \mathrm{H}_{5} \mathrm{CHO}$ to the $\mathrm{C}_{6} \mathrm{H}_{5}+\mathrm{CH}_{2} \mathrm{O}$ channels is estimated to be 1:1.8. The ratio is expected to 
have no temperature dependence. The values of overall rate constant are taken from Hippler et al. [25].

\subsection{Cross reactions between PRF and toluene}

Ignition delay times of PRF/Toluene mixtures were measured at temperatures 1200 to $1600 \mathrm{~K}$ in our recent shock tube study [14]. It was found that the ignition delay times were shortened by the addition of toluene (up to $30 \%$ ) to iso-octane. This effects of toluene addition are attributed to the cross reactions. In order to estimate the species related to cross reactions, time profiles of intermediate species were calculated in the oxidation of n-heptane, iso-octane and toluene at $1500 \mathrm{~K}$ with the current PRF/Toluene mechanism. At higher temperatures, alkane produces mainly alkene before the ignition. For example, ethylene $\left(\mathrm{C}_{2} \mathrm{H}_{4}\right)$ is produced from n-heptane, and propene $\left(\mathrm{C}_{3} \mathrm{H}_{6}\right)$, iso-butene $\left(\mathrm{iC}_{4} \mathrm{H}_{8}\right)$ and allene $\left(\mathrm{aC}_{3} \mathrm{H}_{4}\right)$ are produced from iso-octane. On the other hand, benzyl radical, benzaldehyde, benzene are dominant intermediates during the induction period of toluene oxidation. Therefore, reactions between these intermediates are expected to be important cross reactions. Following three types of reactions are considered in the model.

(i) H atom abstraction reactions (R3).

$$
\mathrm{RH}+\mathrm{Q} \Leftrightarrow \mathrm{R}+\mathrm{QH}
$$


Here, $\mathrm{RH}$ denotes toluene, benzene and benzaldehyde and $\mathrm{QH}$ denotes n-heptane, iso-octane, $\mathrm{C}_{3} \mathrm{H}_{6}$ and $\mathrm{iC}_{4} \mathrm{H}_{8}$. These reactions of $\mathrm{H}$ atom abstraction have been considered in several modeling studies [4-6]. The rate constants were taken and estimated from literatures [14, 21, 27].

(ii) Recombination reactions between radicals produced from toluene and alkane. Vanhove et al. [13] observed $\mathrm{C}_{6} \mathrm{H}_{5} \mathrm{CH}_{2} \mathrm{CH}_{2} \mathrm{C}\left(\mathrm{CH}_{3}\right)=\mathrm{CH}_{2}$ as a product of PRF/Toluene oxidation in their RCM studies. This molecule is expected to be produced by a recombination reaction of benzyl and iso-butenyl radicals. Therefore, the reaction (R4) is included in the present model.

$$
\mathrm{C}_{6} \mathrm{H}_{5} \mathrm{CH}_{2}+\mathrm{iC}_{4} \mathrm{H}_{7} \Leftrightarrow \mathrm{C}_{6} \mathrm{H}_{5} \mathrm{CH}_{2} \mathrm{CH}_{2} \mathrm{C}\left(\mathrm{CH}_{3}\right)=\mathrm{CH}_{2}
$$

Recombination reactions of alkenyl radicals such as $\mathrm{C}_{2} \mathrm{H}_{3}$ and $\mathrm{C}_{3} \mathrm{H}_{5}$ with benzyl radical and their subsequent reactions were also included. The rate constants of these reactions were estimated from similar reactions of benzyl radical in the toluene mechanism.

(iii) Addition reactions of phenyl radical to alkenes.

As indicated by Fahr et al. [28], this type of reaction proceeds by the combination of addition and $\beta$-scission. The displacement reactions of $\mathrm{C}_{2} \mathrm{H}_{4}, \mathrm{C}_{3} \mathrm{H}_{6}$ and $\mathrm{iC}_{4} \mathrm{H}_{8}$ with phenyl radicals (R5)-(R10), and their subsequent reactions were considered

$$
\mathrm{C}_{6} \mathrm{H}_{5}+\mathrm{C}_{2} \mathrm{H}_{4} \Leftrightarrow \text { Styrene }+\mathrm{H}
$$




$$
\begin{aligned}
& \mathrm{C}_{6} \mathrm{H}_{5}+\mathrm{C}_{3} \mathrm{H}_{6} \Leftrightarrow \mathrm{C}_{6} \mathrm{H}_{5} \mathrm{C}\left(\mathrm{CH}_{3}\right)=\mathrm{CH}_{2}+\mathrm{H} \\
& \mathrm{C}_{6} \mathrm{H}_{5}+\mathrm{C}_{3} \mathrm{H}_{6} \Leftrightarrow \text { Styrene }+\mathrm{CH}_{3} \\
& \mathrm{C}_{6} \mathrm{H}_{5}+\mathrm{C}_{3} \mathrm{H}_{6} \Leftrightarrow \mathrm{C}_{6} \mathrm{H}_{5} \mathrm{CH}_{2} \mathrm{CH}=\mathrm{CH}_{2}+\mathrm{H} 6 \\
& \mathrm{C}_{6} \mathrm{H}_{5}+\mathrm{iC}_{4} \mathrm{H}_{8} \Leftrightarrow \mathrm{C}_{6} \mathrm{H}_{5} \mathrm{C}\left(\mathrm{CH}_{3}\right)=\mathrm{CH}_{2}+\mathrm{CH}_{3} \\
& \left.\mathrm{C}_{6} \mathrm{H}_{5}+\mathrm{iC}_{4} \mathrm{H}_{8} \Leftrightarrow \mathrm{C}_{6} \mathrm{H}_{5} \mathrm{CH}_{2} \mathrm{C}\left(\mathrm{CH}_{3}\right)=\mathrm{CH}_{2}+\mathrm{H} 9\right)
\end{aligned}
$$

Rate constants of these reactions were taken from the estimates of Tsang [29]. For the benzyl radicals, corresponding reactions are endothermic, and therefore not considered in the present model.

Vereechen et al. [30] calculated the potential energy barrier heights for the reaction of $\mathrm{aC}_{3} \mathrm{H}_{4}+\mathrm{C}_{6} \mathrm{H}_{5}$. They also derived the channel specific rate constants of this reaction based on the RRKM-master equation analysis. At high temperatures, dominant reaction channels are $\mathrm{H}$ atom abstraction $(\mathrm{R} 3),(\mathrm{R} 11)$ and $(\mathrm{R} 12)$. The reaction (R11) produces benzyl radical and acetylene by the addition to double bond followed by $\mathrm{H}$ atom transfer and $\beta$-scission. The reaction ( $\mathrm{R} 12)$ produce indenes $\left(\mathrm{C}_{9} \mathrm{H}_{8}\right)$ and $\mathrm{H}$ atom by the addition to double bond followed by $\mathrm{H}$ atom transfer and ring formation.

$$
\begin{aligned}
& \mathrm{C}_{6} \mathrm{H}_{5}+\mathrm{aC}_{3} \mathrm{H}_{4} \Leftrightarrow \mathrm{C}_{6} \mathrm{H}_{5} \mathrm{CH}_{2}+\mathrm{C}_{2} \mathrm{H}_{2} \\
& \mathrm{C}_{6} \mathrm{H}_{5}+\mathrm{aC}_{3} \mathrm{H}_{4} \Leftrightarrow \mathrm{C}_{9} \mathrm{H}_{8}+\mathrm{H}
\end{aligned}
$$

Corresponding benzyl reactions with allene were included in the present model. In case 
of benzyl radical, $\mathrm{H}$ atom abstraction reactions (R3), (R13) and (R14) are need to be considered.

$$
\begin{aligned}
& \mathrm{C}_{6} \mathrm{H}_{5} \mathrm{CH}_{2}+\mathrm{aC}_{3} \mathrm{H}_{4} \Leftrightarrow \mathrm{C}_{6} \mathrm{H}_{5} \mathrm{CH}_{2} \mathrm{CH}_{2}+\mathrm{C}_{2} \mathrm{H}_{2} \\
& \mathrm{C}_{6} \mathrm{H}_{5} \mathrm{CH}_{2}+\mathrm{aC}_{3} \mathrm{H}_{4} \Leftrightarrow \mathrm{C}_{10} \mathrm{H}_{10} \text { (dihydronaphthalene ) }+\mathrm{H}
\end{aligned}
$$

Reactions (R13) and (14) are exothermic, and their rate constants are assumed to be equal to those of corresponding $\mathrm{aC}_{3} \mathrm{H}_{4}+\mathrm{C}_{6} \mathrm{H}_{5}$ reactions. Subsequent reactions of $\mathrm{C}_{10} \mathrm{H}_{10}$ are taken from Da Costa et al [31].

\section{Results and discussion}

For validating the present PRF/Toluene model, we have compared the model predictions with some representative experimental results. All calculations were performed by using CHEMKIN 4.1 program package [32]. For the simulation of ignition delay times behind reflected shocks wave and species profile in flow reactor, an adiabatic homogeneous reactor is assumed. In general, the present model predicts well the reactivity of toluene and PRF/Toluene mixtures over wide range of temperatures and pressures. Figure 2 shows the pressure dependence of ignition delay times of toluene behind reflected shock waves at pressures from 2 to 50 atm $[33,34]$. The ignition delay times of toluene at $50 \mathrm{~atm}$ [34] are compared in Fig. 3 with different equivalence ratios 
of $0.25,0.5$ and 1.0. Although the agreement is quite satisfactory at 12 and $50 \mathrm{~atm}$, there is some discrepancy in high temperature data at 2 atm, as can be seen in Fug. 2. Figure 4 shows the comparison of $\mathrm{CO}+\mathrm{CO}_{2}$ mole fraction in the oxidation of toluene at $12.5 \mathrm{~atm}$ obtained by a flow reactor experiments [7]. It is found that products of the toluene oxidation in a flow reactor experiments (not only $\mathrm{CO}+\mathrm{CO}_{2}$ but also other stable products) are well reproduced by the present model. Figure 5 shows the comparison of the ignition delay times of PRF/Toluene mixtures at 25 and $50 \mathrm{~atm}$ [1]. The species mole fractions in the oxidation of PRF/Toluene at 12.5 atm obtained by a flow reactor experiments [7] are compared in Fig. 6. Those figures indicate that the present model well predicts the reactivity of PRF/Toluene mixtures at wide range of temperature and pressure. The ignition delay times of PRF with the addition of toluene obtained by shock tube experiments [14] are compared with the simulation results in Fig. 7. Model predictions with cross reactions (lines) agree with experiments better than the model without cross reactions (dashed lines). Although the acceleration by the addition of toluene to iso-octane is not reproduced, agreements in toluene/iso-octane mixtures are largely improved by the inclusion of cross reactions.

Reaction path and sensitivity analysis were performed for the oxidation of toluene and $\mathrm{PRF} /$ Toluene mixtures at various temperatures and pressures in order to understand 
the ignition mechanism of toluene and the kinetic interactions between PRF and toluene.

At low temperatures $(\mathrm{T}<1100 \mathrm{~K})$, toluene reacts mainly with $\mathrm{OH}$ and $\mathrm{C}_{6} \mathrm{H}_{5} \mathrm{O}$ radicals to form benzyl radical. Benzyl radical reacts with molecular oxygen to form benzyl-peroxy radical (R15).

$$
\mathrm{C}_{6} \mathrm{H}_{5} \mathrm{CH}_{2}+\mathrm{O}_{2}=\mathrm{C}_{6} \mathrm{H}_{5} \mathrm{CH}_{2} \mathrm{OO}
$$

Internal $\mathrm{H}$-atom abstraction reactions of benzyl-peroxy radical are slow, and the decomposition reactions, (R16) and (R17), are the dominant route of consumption of the benzyl-peroxy radical.

$$
\begin{aligned}
& \mathrm{C}_{6} \mathrm{H}_{5} \mathrm{CH}_{2} \mathrm{OO}=\mathrm{C}_{6} \mathrm{H}_{5} \mathrm{CHO}+\mathrm{OH} \\
& \mathrm{C}_{6} \mathrm{H}_{5} \mathrm{CH}_{2} \mathrm{OO}=\mathrm{C}_{6} \mathrm{H}_{5} \mathrm{O}+\mathrm{CH}_{2} \mathrm{O}
\end{aligned}
$$

The reaction (R16) has high sensitivity to the ignition because this reaction is a main source of $\mathrm{OH}$ in stead of the $\mathrm{H}_{2} \mathrm{O}_{2}=2 \mathrm{OH}$ and $\mathrm{H}+\mathrm{O}_{2}=\mathrm{O}+\mathrm{OH}$ reactions which are important at higher temperatures. Therefore inclusion of these benzyl $+\mathrm{O}_{2}$ reactions (R15-R17) is crucial to predict the ignition delay of toluene.

Sivaramakrishnan et al. [11] used collisional rate constants for $\mathrm{C}_{6} \mathrm{H}_{5} \mathrm{CH}_{2}+\mathrm{HO}_{2}=$ $\mathrm{C}_{6} \mathrm{H}_{5} \mathrm{CHO}+\mathrm{H}+\mathrm{OH}$ and $\mathrm{C}_{6} \mathrm{H}_{5} \mathrm{CH}_{2}+\mathrm{HO}_{2}=\mathrm{C}_{6} \mathrm{H}_{5}+\mathrm{CH}_{2} \mathrm{O}+\mathrm{OH}$ as important branching reactions of benzyl radical. These lumped reactions are one of the most sensitive 
reactions for the ignition of toluene at high pressures and composed of following elementary reactions: $\mathrm{C}_{6} \mathrm{H}_{5} \mathrm{CH}_{2}+\mathrm{HO}_{2}=\mathrm{C}_{6} \mathrm{H}_{5} \mathrm{CH}_{2} \mathrm{O}+\mathrm{OH}, \mathrm{C}_{6} \mathrm{H}_{5} \mathrm{CH}_{2} \mathrm{O}=\mathrm{C}_{6} \mathrm{H}_{5} \mathrm{CHO}+$ $\mathrm{H}$ and $\mathrm{C}_{6} \mathrm{H}_{5} \mathrm{CH}_{2} \mathrm{O}=\mathrm{C}_{6} \mathrm{H}_{5}+\mathrm{CH}_{2} \mathrm{O}$. Andrae et al. [6] included the elementary reaction of $\mathrm{C}_{6} \mathrm{H}_{5} \mathrm{CH}_{2}+\mathrm{HO}_{2}=\mathrm{C}_{6} \mathrm{H}_{5} \mathrm{CH}_{2} \mathrm{O}+\mathrm{OH}$ in their model with two orders of magnitude less than collisional rate constant. They also included $\mathrm{C}_{6} \mathrm{H}_{5} \mathrm{CH}_{2}+\mathrm{O}_{2}=\mathrm{C}_{6} \mathrm{H}_{5}+\mathrm{CH}_{2} \mathrm{O}+\mathrm{O}$ as a branching reaction with the rate constants which was adjusted to agree with measured ignition delay times for toluene. In our model, we used rate constants for $\mathrm{C}_{6} \mathrm{H}_{5} \mathrm{CH}_{2}+\mathrm{O}_{2}$ and $\mathrm{C}_{6} \mathrm{H}_{5} \mathrm{CH}_{2} \mathrm{O}$ obtained by theoretically as mentioned before. The $\mathrm{C}_{6} \mathrm{H}_{5} \mathrm{CH}_{2}+\mathrm{HO}_{2}$ reaction is important only around $1300-1600 \mathrm{~K}$ and its rate constant is assumed to be $5.00 \times 10^{12} \mathrm{~cm}^{3} / \mathrm{mol} / \mathrm{s}$ in order to obtain good agreement with ignition delay times of toluene at high temperature.

For the kinetic interactions between PRF and toluene, it is indicated that the reaction of allene with benzyl radical is important for the kinetic interaction. In the iso-octane oxidation, allene mainly reacts with $\mathrm{H}$ atom. On the other hand, allene reacts dominantly with benzyl radical (reactions (R13) and (R14)) in the oxidation of iso-octane/toluene mixtures. Therefore allene reactions with benzyl or phenyl reactions have large effects in the mixtures of toluene and the branched alkane which produces allene. Other alkene reactions with aromatic radicals are also other candidates for the 
important cross reactions. However, experimental and theoretical study on the reaction of alkene with aromatic radical is very scarce [35]. Detailed investigation of these important reactions for PRF/Toluene mixtures is open for future study.

\section{Conclusions}

A detailed chemical kinetic model for PRF/Toluene has been proposed. The present model is constructed with a focus on the low temperature kinetics of toluene which has not been well understood in the past. The kinetic interactions between PRF and Toluene are also examined in this work. It is confirmed that the present model predicts the ignition characteristics of toluene and PRF/Toluene at the wide range of temperatures $(500-1700 \mathrm{~K})$ and pressures $(2-50 \mathrm{~atm})$. The reactions of benzyl radical with molecular oxygen determine the reactivity of toluene at low temperatures. For kinetic interactions between PRF and toluene, it is suggested that the reactions between alkene and aromatic radicals are important to predict the ignition delay times in the mixtures of branched alkane and aromatic fuels. The reaction of allene and benzyl radical is especially important in the mixtures of iso-octane and toluene. For further understanding of the kinetic interactions, the detailed investigations of alkene with aromatic radicals are required. 


\section{Acknowledgments}

The work at LLNL was also performed under the auspices of the U.S. Department of

Energy by Lawrence Livermore National Laboratory under Contract

DE-AC52-07NA27344. 


\section{References}

[1] B.M. Gauthier, D.F. Davidson, R.K. Hanson, Combust. Flame 139 (2004) 300-311.

[2] W.J. Pitz, N.P. Cernansky, F.L. Dryer, F.N. Egolfopoulos, J.T. Farrell, D.G. Friend, H. Pitsch, Development of an Experimental Database and Chemical Kinetic Models for Surrogate Gasoline Fuels, SAE 2007-01-0175 (2007).

[3] R. Ogink, V. Golovitchev, Gasoline HCCI Modeling: An Engine Cycle Simulation Code with a Multi-Zone Combustion Model, SAE 2002-01-1745 (2002).

[4] C.V. Naik, W.J. Pitz, M. Sjöberg, J.E. Dec, J. Orme, H.J. Curran, J.M. Simmie, C.K. Westbrook, Detailed Chemical Kinetic Modeling of Surrogate Fuels for Gasoline and Application to an HCCI Engine, 2005 Joint Meeting of the U.S. Sections of The Combustion Institute (2005).

[5] J. Andrae, D. Johansson, P. Björnbom, P. Risberg, G. Kalghatgi, Combust. Flame 140 (2005) 267-286.

[6] J.C.G. Andrae, P. Björnbom, R.F. Cracknell, G.T. Kalghatgi, Combust. Flame 149 (2007) 2-24.

[7] M. Chaos, Z. Zhao, A. Kazakov, P. Gokulakrishnan, M. Angioletti, F.L. Dryer, A PRF+Toluene Surrogate Fuel Model for Simulating Gasoline Kinetics, $5^{\text {th }}$ US Combustion Meeting (2007). 
[8] D.F. Davidson, B.M. Gauthier, R.K. Hanson, Combust. Flame 30 (2005) 1175-1182.

[9] G. Mittal, C.J. Sung, Combust. Flame 150 (2007) 355-368.

[10] R. Sivaramakrishnan, R.S. Tranter, K. Brezinsky, Combust. Flame 139 (2004) 340-350.

[11] R. Sivaramakrishnan, R.S. Tranter, K. Brezinsky, Proc. Combust. Inst. 30 (2005) 1165-1173.

[12] S.D. Klotz, K. Brezinsky, I. Glassman, Proc. Combust. Inst. 27 (1998) 337-344.

[13] G. Vanhove, G. Petit, R. Minetti, Combust. Flame 145 (2006) 521-532.

[14] Y. Sakai, H. Ozawa, T. Ogura, A. Miyoshi, M. Koshi, W.J. Pitz, Effects of Toluene Addition to Primary Reference Fuel at High Temperature, SAE 2007-01-4104 (2007).

[15] W.J. Pitz, R. Seiser, J.W. Bozzelli, I. Da Costa, R. Fournet, F. Billaud, F. Battin-Leclerc, K. Seshadri, C.K. Westbrook, Chemical Kinetic Characterization of the Combustion of Toluene, Proc. of the $2^{\text {nd }}$ Joint Meeting of the U.S. Sections of the Combustion Institute (2001).

[16] T. Ogura, Y. Sakai, A. Miyoshi, M. Koshi, P. Dagaut, Energy \& Fuels 21 (2007) 3233-3239.

[17] M.A. Oehlschlaeger, D.F. Davidson, R.K. Hanson, Combust. Flame 147 (2006) 195-208. 
[18] T. Seta, M. Nakajima, A. Miyoshi, J. Phys. Chem. A 110 (2006) 5081-5090.

[19] M.A. Oehlschlaeger, D.F. Davidson, R.K. Hanson, J. Phys. Chem. A 110 (2006) 9867-9873.

[20] M.A. Oehlschlaeger, D.F. Davidson, R.K. Hanson, Thermal Decomposition of Toluene: Overall Rate and Branching Ratio, WSSCI Fall 2005 Meeting (2005).

[21] R. Bounaceur, I. Da Costa, R. Fournet, F. Billaud, F. Battin-Leclerc, Int. J. Chem. Kinet. 37 (2005) 25-49.

[22] Gaussian 03, Revision C.02, M.J. Frisch, G.W. Trucks, H.B. Schlegel, G.E. Scuseria, M.A. Robb, J.R. Cheeseman, J.A. Montgomery Jr., T. Vreven, K.N. Kudin, J.C. Burant, J.M. Millam, S.S. Iyengar, J. Tomasi, V. Barone, B. Mennucci, M. Cossi, G. Scalmani, N. Rega, G.A. Petersson, H. Nakatsuji, M. Hada, M. Ehara, K. Toyota, R. Fukuda, J. Hasegawa, M. Ishida, T. Nakajima, Y. Honda, O. Kitao, H. Nakai, M. Klene, X. Li, J.E. Knox, H.P. Hratchian, J.B. Cross, C. Adamo, J. Jaramillo, R. Gomperts, R.E. Stratmann, O. Yazyev, A.J. Austin, R. Cammi, C. Pomelli, J.W. Ochterski, P.Y. Ayala, K. Morokuma, G.A. Voth, P. Salvador, J.J. Dannenberg, V.G. Zakrzewski, S. Dapprich, A.D. Daniels, M.C. Strain, O. Farkas, D.K. Malick, A.D. Rabuck, K. Raghavachari, J.B. Foresman, J.V. Ortiz, Q. Cui, A.G. Baboul, S. Clifford, J. Cioslowski, B.B. Stefanov, G. Liu, A. Liashenko, P. Piskorz, I. Komaromi, R.L. Martin, D.J. Fox, T. Keith, M.A. 
Al-Laham, C.Y. Peng, A. Nanayakkara, M. Challacombe, P.M.W. Gill, B. Johnson, W.

Chen, M.W. Wong, C. Gonzalez, J.A. Pople, Gaussian, Inc., Wallingford CT, (2004).

[23] Y.Murakami, T.Oguchi, K.Hashimoto, Y.Nosaka, J. Phys. Chem., A (2008) in press

[24] S.J. Klippenstein, A.F. Wagner, R.C. Dunbar, D.M. Wardlaw, S.H. Robertson, J.A. Miller, Varilfex Version 1.13m (2003).

[25] H. Hippler, C. Reihs, J. Troe, Proc. Combust. Inst. 23 (1990) 37-43.

[26] J.L. Emdee, K. Brezinsky, I. Glassman, J. Phys. Chem. 96 (1992) 2151-2161.

[27] I. Da Costa, R. Fournet, F. Billaud, F. Battin-Leclerc, Int. J. Chem. Kinet. 35 (2003) 503-524.

[28] A. Fahr, S.E. Stein, Proc. Combust. Inst. 22 (1988) 1023-1029.

[29] W. Tsang, J. Phys. Chem. Ref. Data 20 (1991) 221-273.

[30] L. Vereecken, J. Peeters, Phys. Chem. Chem. Phys. 5 (2003) 2807-2817.

[31] F. Battin-Leclerc, R. Bounaceur, N. Belmekki, P.A. Glaude, Int. J. Chem. Kinet. 38 (2006) 284-302.

[32] R.J. Kee, F.M. Rupley, J.A. Miller, M.E. Coltrin, J.F. Grcar, E. Meeks, H.K. Moffat, A.E. Lutz, G. Dixon-Lewis, M.D. Smooke, J. Warnatz, G.H. Evans, R.S. Larson, R.E. Mitchell, L.R. Petzold, W.C. Reynolds, M. Caracotsios, W.E. Stewart, P. Glarborg, C. Wang, C.L. McLellan, O. Asigun, W.G. Houf, C.P. Chou, S.F. Miller, P. Ho, P.D. Young, 
D.W. Hodgson, M.V. Petrova, K.V. Puduppakkam, CHEMIKIN Release 4.1, Reaction Design, San Diego, CA, (2006).

[33] Y. Sakai, T. Inamura, T. Ogura, M. Koshi, W.J. Pitz, Detailed Kinetic Modeling of

Toluene Combustion over a Wide Range of Temperature and Pressure, SAE 2007-01-1885 (2007).

[34] H.S. Shen, J. Vanderover, M.A. Oehlschlaeger, submitted to this symposium.

[35] I.V. Tokmakov, M.C. Lin, J. Phys. Chem. A 108 (2004) 9697-9714. 


\section{Figure captions}

Fig.1. Potential energy currves for the $\mathrm{C}_{6} \mathrm{H}_{5} \mathrm{CH}_{2}+\mathrm{O}$ reaction obtained by the B3LYP/6-31G(d) level of theory.

Fig.2. Comparisons of measured and simulated ignition delay times of toluene at the equivalence ratio of 0.5 and $1.2 \%$ fuels diluted in Ar or air behind reflected shock waves at 2 [33], 15 and 50 atm [34]. Solid curves: Present model, dashed curves: Pitz model.

Fig.3. Comparisons of measured and simulated ignition delay times of toluene behind reflected shock waves at $50 \mathrm{~atm}[34]$.

Fig.4. Comparisons of measured and simulated $\mathrm{CO}+\mathrm{CO}_{2}$ mole fractions in toluene oxidation obtained by the flow reactor experiments at 12 atm as a function of initial temperature [7]. Solid curves: Present model, dashed curves: Pitz model.

Fig.5. Comparisons of measured and simulated ignition delay times of stoichiometric PRF/Toluene mixtures (n-heptane/iso-octane/toluene $=17 / 63 / 20$ ) behind reflected shock waves at pressures 25 and $50 \mathrm{~atm}$ [1]. Curves: Present model.

Fig.6. Comparisons of measured and simulated species mole fractions in PRF/toluene oxidation obtained by a flow reactor experiments at 12.5 atm as a function of initial temperature in PRF/toluene oxidation [7]. Curves: Present model.

Fig.7. Comparisons of measured and simulated ignition delay times of stoichiometric 
$\mathrm{PRF} /$ Toluene mixtures at $1500 \mathrm{~K}$ and 2 atm as a function of toluene concentration [14]. 


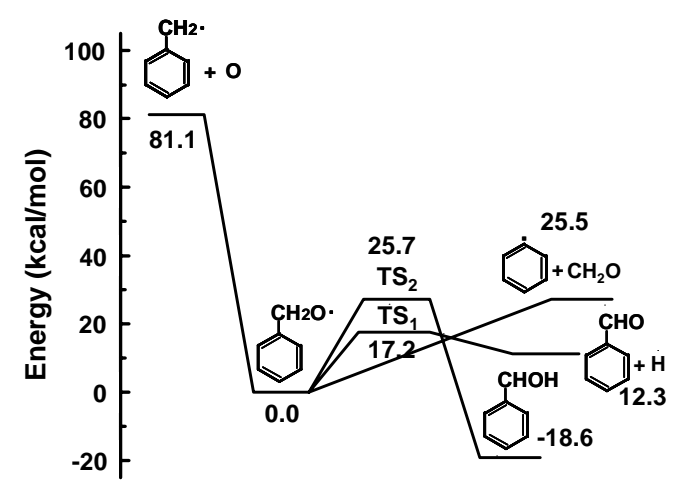

Fig.1. Potential energy currves for the $\mathrm{C}_{6} \mathrm{H}_{5} \mathrm{CH}_{2}+\mathrm{O}$ reaction obtained by the B3LYP/6-31G(d) level of theory. 


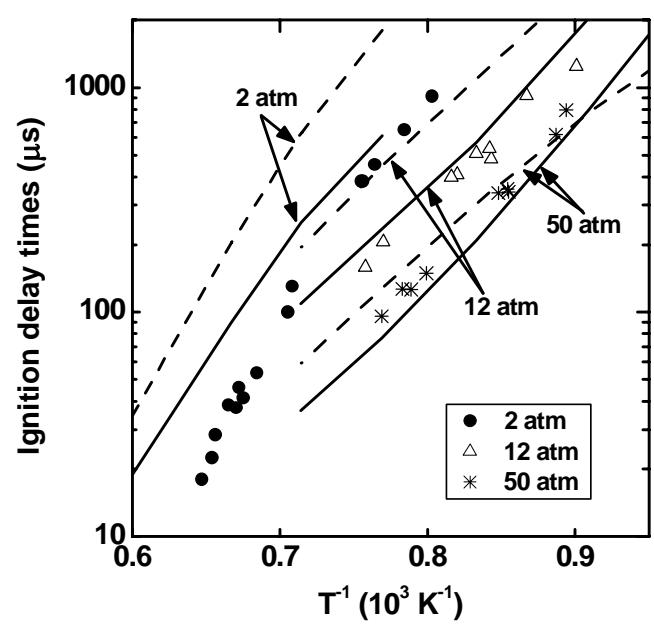

Fig.2. Comparisons of measured and simulated ignition delay times of toluene at the equivalence ratio of 0.5 and $1.2 \%$ fuels diluted in Ar or air behind reflected shock waves at 2 [33], 15 and 50 atm [34]. Solid curves: Present model, dashed curves: Pitz model. 


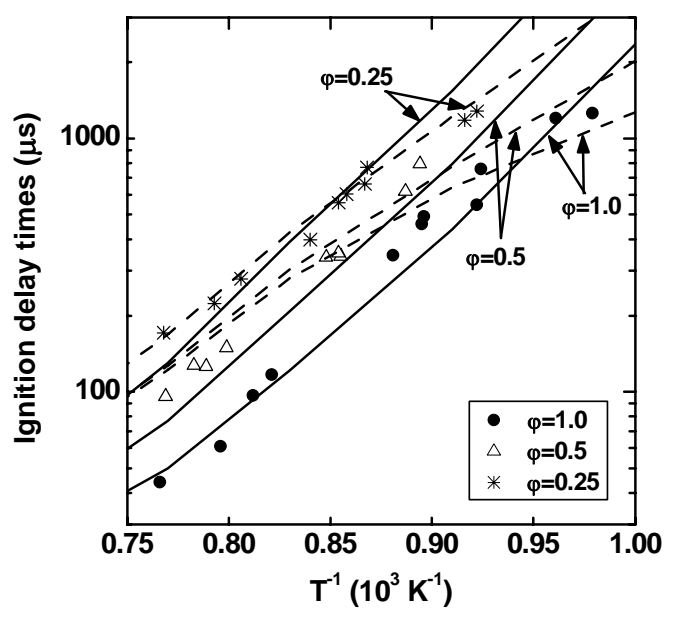

Fig.3. Comparisons of measured and simulated ignition delay times of toluene behind reflected shock waves at 50 atm [34]. Solid curves: Present model, dashed curves: Pitz model. 


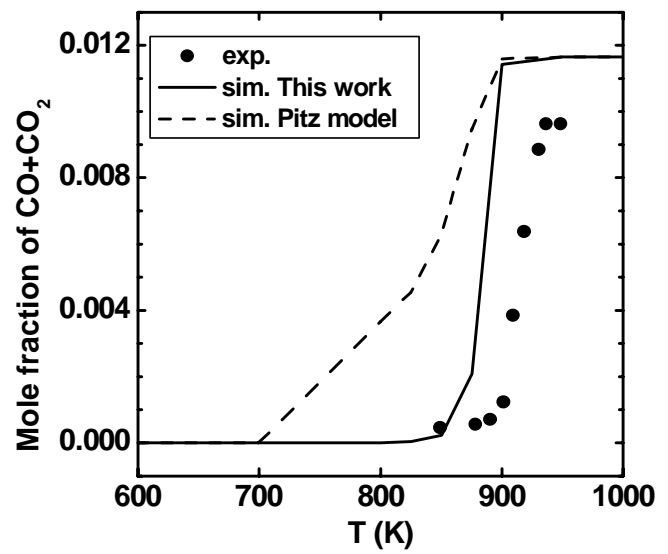

Fig.4. Comparisons of measured and simulated $\mathrm{CO}+\mathrm{CO}_{2}$ mole fractions in toluene oxidation obtained by the flow reactor experiments at 12 atm as a function of initial temperature [7]. Solid curves: Present model, dashed curves: Pitz model. 


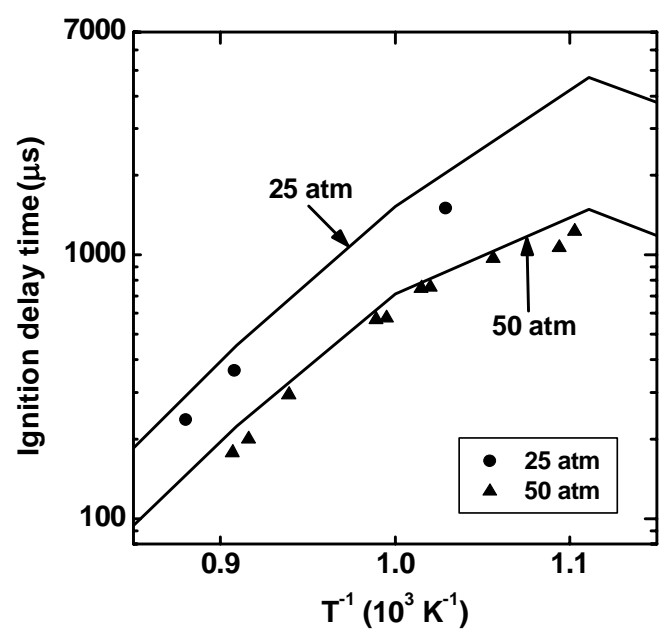

Fig.5. Comparisons of measured and simulated ignition delay times of stoichiometric $\mathrm{PRF} /$ Toluene mixtures (n-heptane/iso-octane/toluene=17/63/20) behind reflected shock waves at pressures 25 and 50 atm [1]. Curves: Present model. 


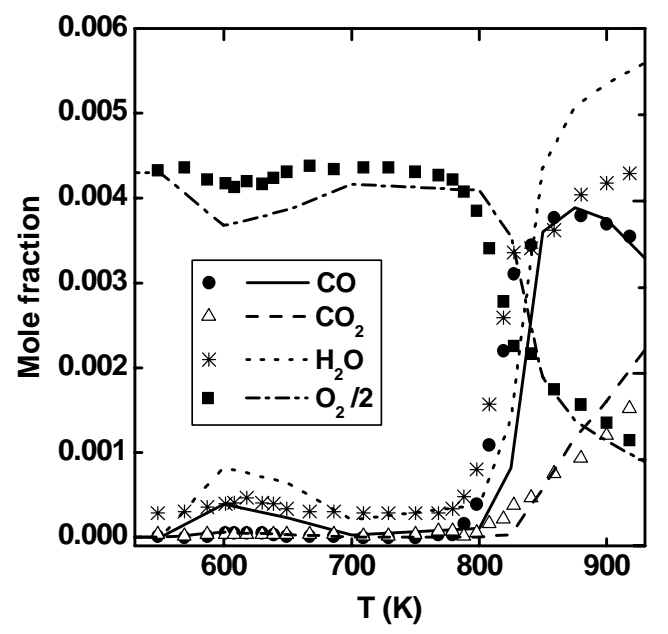

Fig.6. Comparisons of measured and simulated species mole fractions in PRF/toluene oxidation obtained by a flow reactor experiments at 12.5 atm as a function of initial temperature in PRF/toluene oxidation [7]. Curves: Present model. 


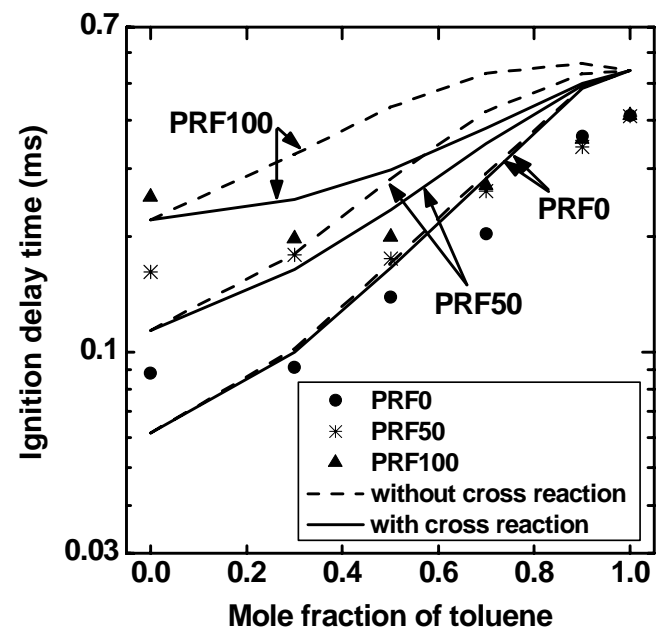

Fig.7. Comparisons of measured and simulated ignition delay times of stoichiometric

$\mathrm{PRF} /$ Toluene mixtures at $1500 \mathrm{~K}$ and 2 atm as a function of toluene concentration [14]. 